\title{
Clinical evaluation of ridge augmentation using autogenous tooth bone graft material: case series study
}

\author{
Ji-Young Lee ${ }^{1}$, Young-Kyun Kim ${ }^{1,3}$, Yang-Jin Yi ${ }^{2}$, Joon-Ho Choi ${ }^{4}$ \\ ${ }^{1}$ Departments of Oral and Maxillofacial Surgery and ${ }^{2}$ Prosthodontics, Section of Dentistry, Seoul National University Bundang Hospital, \\ Seongnam, ${ }^{3}$ School of Dentistry, Seoul National University, Seoul, Korea, ${ }^{4}$ The Hill School, Pottstown, PA, USA
}

Abstract (J Korean Assoc Oral Maxillofac Surg 2013;39:156-160)

Objectives: Interest in bone graft material has increased with regard to restoration in cases of bone defect around the implant. Autogenous tooth bone graft material was developed and commercialized in 2008. In this study, we evaluated the results of vertical and horizontal ridge augmentation with autogenous tooth bone graft material.

Materials and Methods: This study targeted patients who had vertical or horizontal ridge augmentation using AutoBT from March 2009 to April 2010. We evaluated the age and gender of the subject patients, implant stability, adjunctive surgery, additional bone graft material and barrier membrane, post-operative complication, implant survival rate, and crestal bone loss.

Results: We performed vertical and horizontal ridge augmentation using powder- or block-type autogenous tooth bone graft material, and implant placement was performed on nine patients (male: 7, female: 2 ). The average age of patients was $49.88 \pm 12.98$ years, and the post-operative follow-up period was $35 \pm 5.31$ months. Post-operative complications included wound dehiscence (one case), hematoma (one case), and implant osseointegration failure (one case; survival rate: $96 \%$ ); however, there were no complications related to bone graft material, such as infection. Average marginal bone loss after one-year loading was $0.12 \pm 0.19 \mathrm{~mm}$. Therefore, excellent clinical results can be said to have been obtained.

Conclusion: Excellent clinical results can be said to have been obtained with vertical and horizontal ridge augmentation using autogenous tooth bone graft material.

Key words: Autogenous tooth bone graft material, Ridge augmentation

[paper submitted 2013. 6. 21 / revised 2013. 8. 7 / accepted 2013. 8. 8]

\section{Introduction}

Over time after tooth extraction, the length and width of the alveolar ridge are inevitably reduced; this causes the lack of vertical and horizontal bones, one of the difficult problems to address during the placement of implant. In particular, the maxillary anterior is very important aesthetically, and

\section{Yang-Jin $\mathrm{Yi}$}

Department of Prosthodontics, Section of Dentistry, Seoul National University Bundang Hospital, 82 Gumi-ro 173beon-gil, Bundang-gu, Seongnam 463-707, Korea

TEL: +82-31-787-7541 FAX: +82-31-787-4068

E-mail: kyk0505@snubh.org

(c) This is an open-access article distributed under the terms of the Creative Commons Attribution Non-Commercial License (http://creativecommons.org/licenses/by-nc/3.0/), which permits unrestricted non-commercial use, distribution, and reproduction in any medium, provided the original work is properly cited.

Copyright (C) 2013 The Korean Association of Oral and Maxillofacial Surgeons. All rights reserved. the amount of soft and hard tissues should be sufficient for predictable aesthetics. The posterior also needs enough amount of bone to make prosthesis of the appropriate size and with desirable implant-crown ratio. Therefore, alveolar ridge augmentation has become a common surgery option when implant is placed in a defective area of the alveolar bone, and many methods and materials for this operation have been studied ${ }^{1-4}$. For restoration in case of bone defect, autogenous bone is known as the material with the most excellent osteogenetic effect and is biocompatible. Still, the amount of collected bone is limited, and the donor site also requires additional surgery. Moreover, allogenic bone and xenogenic bone are very expensive, and there is risk of infection. On the other hand, alloplastic material does not have osteogenesis and osteoinduction at all. To remedy such shortcomings, new bone graft material using extracted autogenous tooth (AutoBT; Korea Tooth Bank, Seoul, Korea)

This study was supported by a grant of the Korea Healthcare Technology R\&D Project, Ministry of Health and Welfare, Republic of Korea (A102065). 
has been developed and is being used ${ }^{5,6}$. In this study, we reported the successful clinical result that we obtained from alveolar ridge augmentation and implant placement using the recently developed autogenous tooth bone graft material in the edentulous area characterized by highly insufficient vertical and horizontal bones.

\section{Materials and Methods}

This study targeted patients who had vertical or horizontal ridge augmentation using AutoBT from March 2009 to April 2010. It was conducted with the approval of Seoul National University Bundang Hospital's institutional review board (IRB No. B-0905-076-010).

Inclusion criteria

1) Knife-edge ridge in the anterior and posterior areas

2) Case wherein the height of the residual bone to the sinus floor and inferior alveolar canal is insufficient in the area of implant placement

3) Patient who is mentally healthy or whose systemic disease is controlled

4) Patient who has a tooth to be extracted for AutoBT treatment

5) Patient who received instruction on the purpose of the clinical study and gave his/her consent

Exclusion criteria

1) Patient who has had bone graft in the surgery area

2) Patient who has had radiation therapy

3) Patient who has sinus disease history or symptoms

4) Patient who has acute infection

\section{Treatment procedure}

One oral and maxillofacial surgeon performed surgery in Seoul National University Bundang Hospital. According to the status of the surgical site, horizontal or vertical ridge augmentation and ridge splitting accompanying guided bone regeneration (GBR) were performed. Based on the size of the defect, the use of mixture with other bone graft material, the use of barrier, and the need for sinus elevation were decided. The operator decided at the time of surgery on simultaneous or delayed implant placement. All implants were placed using a two-stage procedure. After 2-8 months' (average: 4.4 months) healing period, a second surgery was performed. Prosthetic restoration was performed by one prosthodontist.

\section{Clinical evaluation}

We evaluated the age and gender of the subject patients, implant stability, adjunctive surgery, additional bone graft material and barrier membrane, post-operative complication, implant survival rate, and crestal bone loss. The primary and secondary stabilities of the implant were measured using Osstell Mentor (Integration Diagnostics, Goteborg, Sweden).

\section{Radiographic evaluation of crestal bone loss}

Based on the radiograph taken right after the surgery, the amount of crestal bone resorption was measured by comparing with the periapical radiograph taken at 1-year follow-up period after prosthetic delivery. Based on the length of the placed implants, the magnification rate of the periapical radiograph was evaluated; for the amount of alveolar crest bone resorption, the average amount of mesial and distal crestal bone resorption was measured.

\section{Results}

We manufactured 29 teeth extracted from a total of 9 patients (males: 7, females: 2) in the form of AutoBT powder or block, performed vertical and horizontal ridge augmentation, and then placed implants.(Tables 1,2) A total of 26 implants were placed, and both AutoBT block and powder were used in 11 areas. Powder type only was used in 13 areas, and block type only, in 2 areas. The average age of the patients was $49.88 \pm 12.98$ years (minimum: 24 , maximum: 67). For systemic diseases, one patient was a smoker who had liver disease (controlled); another patient was also a smoker, and one had a history of mental illness. The average healing period after the surgery was $4.40 \pm$ 1.68 months, and the average observation period after the surgery was $35.00 \pm 5.31$ months. The average loading period after the installation of prosthesis was $30.81 \pm 5.81$ months. According to the judgment of the operator, 9 implants were placed on 3 patients simultaneously with ridge augmentation; 17 implants were placed on 6 patients after a healing period of $6.06 \pm 3.52$ months. A total of 24 implants were placed on the maxilla, with 2 implants placed on the mandible. In the 9 areas with major defects, allobone (DBX; Synthes, Westchester, PA, USA/Allograft), xenobone (Bio-Oss; Osteohealth, Shirley, NY, USA), and synthetic bone (Osteon; Genoss, Suwon, Korea) were used together; in the rest of the areas, only AutoBT was used. Membranes were used in all 
Table 1. Summary of case 1

\begin{tabular}{|c|c|c|c|c|c|c|c|}
\hline Patient No. & Age (yr) & Gender & $\begin{array}{l}\text { Extracted } \\
\text { tooth used (n) }\end{array}$ & Operation site & Type of surgery & $\begin{array}{l}\text { Type of AutoBT } \\
\text { (block/powder) }\end{array}$ & Complication \\
\hline \multirow[t]{6}{*}{1} & 47 & M & 6 & 16 & Horizontal RA & Powder & No \\
\hline & & & & 14 & Horizontal RA & Powder & No \\
\hline & & & & 12 & Horizontal RA & Powder & No \\
\hline & & & & 22 & Horizontal RA & Powder & No \\
\hline & & & & 24 & Horizontal RA & Powder & No \\
\hline & & & & 26 & Horizontal RA & Powder & No \\
\hline \multirow[t]{2}{*}{2} & 49 & $\mathrm{~F}$ & 4 & 12 & Horizontal RA & Both & WD \\
\hline & & & & 22 & Horizontal RA & Both & WD \\
\hline 3 & 24 & M & 1 & 22 & Horizontal RA & Both & No \\
\hline \multirow[t]{2}{*}{4} & 63 & $\mathrm{~F}$ & 1 & 11 & Ridge splitting and GBR & Powder & No \\
\hline & & & & 21 & Ridge splitting and GBR & Powder & No \\
\hline \multirow[t]{2}{*}{5} & 67 & M & 2 & 25 & Vertical and horizontal RA & Powder & No \\
\hline & & & & 26 & Vertical and horizontal RA & Powder & No \\
\hline \multirow[t]{6}{*}{6} & 44 & M & 7 & 15 & Vertical RA & Both & No \\
\hline & & & & 16 & Vertical RA & Both & No \\
\hline & & & & 12 & Horizontal RA & Both & No \\
\hline & & & & 21 & Horizontal RA & Both & No \\
\hline & & & & 45 & Vertical RA & Block & No \\
\hline & & & & 46 & Vertical RA & Powder & No \\
\hline \multirow[t]{4}{*}{7} & 46 & M & 5 & 14 & Vertical RA & Both & No \\
\hline & & & & 15 & Vertical RA & Both & No \\
\hline & & & & 16 & Vertical RA & Both & No \\
\hline & & & & 17 & Vertical RA & Both & No \\
\hline 8 & 62 & M & 1 & 16 & Vertical RA & Block & No \\
\hline \multirow[t]{2}{*}{9} & 47 & M & 2 & 26 & Vertical RA & Powder & Hematoma \\
\hline & & & & 27 & Vertical RA & Powder & Hematoma \\
\hline
\end{tabular}

(M: male, F: female, RA: ridge augmentation, GBR: guided bone regeneration, WD: wound dehiscence)

AutoBT: Korea Tooth Bank (Seoul, Korea).

Ji-Young Lee et al: Clinical evaluation of ridge augmentation using autogenous tooth bone graft material: case series study. J Korean Assoc Oral Maxillofac Surg 2013

cases except one, with titanium mesh, resorbable membrane (BioGide; Osteohealth/Ossix; OraPharma, Warminster, PA, US), or non-resorbable membrane (TR Goretex; W.L. Gore \& Associates, Flagstaff, AZ, USA) utilized depending on the case. The average primary stability of the placed implants was implant stability quotient (ISQ) 62 (52-86), and the average secondary stability was ISQ 72 (63-85). For post-operative complications, there was one case wherein wound dehiscence developed and another that resulted in hematoma. For the treatment of wound dehiscence, chlorhexidine gluconate gargle and medication were administered; to treat hematoma, pressure dressing was performed. As a result, patients were all successfully treated with conservative care.(Table 1) One implant placed on the \#46 of a 44-year-old male patient after vertical augmentation was removed since it showed mobility 9 months after implant prosthesis. Therefore, the total implant survival rate was $96 \%$. On the area where the implant was removed, another implant was placed again after a three-month healing period, and it functioned successfully after one year of prosthesis. Marginal bone loss after one year of prosthesis was stable at $0.12 \pm 0.19 \mathrm{~mm}$ on the average.

\section{Discussion}

Since the lack of alveolar bone is one of the most prevalent and difficult problems to address in implant surgery, many methods have been developed and used. In the past, autogenous onlay bone graft was mainly used for the improvement of horizontally and vertically shrunken alveolar ridge. Note, however, that it needed additional surgery on the donor site, and predicting the result was difficult since bone resorption varied according to the collection area ${ }^{5}$. Recently, the trend of research reports on the selection of standard treatment for knife-edge ridge has been changing slightly ${ }^{7,8}$. Simion et al. ${ }^{3}$ performed vertical bone augmentation with demineralized freeze-dried bone or autogenous bone chip and non-resorbable membrane and reported a good result after 1-5 years' follow-up. Another paper reported that horizontal bone augmentation with the mixture of autogenous bone and xenobone covered with resorbable membrane resulted in $4.6 \mathrm{~mm}$ bone gain. Another paper reported $3.6 \mathrm{~mm}$ bone gain when only xenobone was used in horizontal bone augmentation $^{7}$. Yet another report stated that vertical bone augmentation using xenobone block type on 9 patients yielded 
Table 2. Summary of case 2

\begin{tabular}{|c|c|c|c|c|c|c|c|}
\hline Patient No. & Operation site & $\begin{array}{c}\text { Immediate/Delayed } \\
\text { implant placement }\end{array}$ & Implant system & $\begin{array}{l}\text { Length } \\
(\mathrm{mm})\end{array}$ & $\begin{array}{l}\text { Diameter } \\
(\mathrm{mm})\end{array}$ & $\begin{array}{l}\text { Bone loss } \\
(\mathrm{mm})\end{array}$ & $\begin{array}{l}\text { Loading period } \\
\text { (mo) }\end{array}$ \\
\hline \multirow[t]{6}{*}{1} & 16 & Immediate & CMI & 10 & 5 & 0 & 29 \\
\hline & 14 & Immediate & CMI & 11.5 & 4 & 0.2 & 29 \\
\hline & 12 & Immediate & CMI & 11.5 & 4 & 0.4 & 29 \\
\hline & 22 & Immediate & CMI & 11.5 & 4 & 0.4 & 29 \\
\hline & 24 & Immediate & CMI & 11.5 & 4 & 0.2 & 29 \\
\hline & 26 & Immediate & CMI & 11.5 & 5 & 0 & 29 \\
\hline \multirow[t]{2}{*}{2} & 12 & Delayed & CMI & 13 & 4 & 0.2 & 26 \\
\hline & 22 & Delayed & CMI & 13 & 4 & 0.2 & 26 \\
\hline 3 & 22 & Delayed & CMI & 11.5 & 3.5 & 0 & 19 \\
\hline \multirow[t]{2}{*}{4} & 11 & Immediate & Osseospeed & 11 & 4 & 0 & 31 \\
\hline & 21 & Immediate & Osseospeed & 11 & 4 & 0 & 31 \\
\hline \multirow[t]{2}{*}{5} & 25 & Delayed & TS III & 13 & 4 & 0.2 & 29 \\
\hline & 26 & Delayed & TS III & 13 & 4.5 & 0.8 & 29 \\
\hline \multirow[t]{6}{*}{6} & 15 & Delayed & GS III & 11.5 & 4.5 & 0 & 28 \\
\hline & 16 & Delayed & GS III & 11.5 & 5 & 0 & 28 \\
\hline & 12 & Delayed & GS III & 11.5 & 3.5 & 0 & 28 \\
\hline & 21 & Delayed & GS III & 11.5 & 3.5 & 0 & 28 \\
\hline & 45 & Delayed & GS III & 8.5 & 4 & 0.2 & 28 \\
\hline & 46 & Delayed & GS III & 8.5 & 5 & Failure & - \\
\hline \multirow[t]{4}{*}{7} & 14 & Delayed & TS III & 10 & 4 & 0 & 16 \\
\hline & 15 & Delayed & TS III & 10 & 4 & 0 & 16 \\
\hline & 16 & Delayed & TS III & 11.5 & 5 & 0 & 16 \\
\hline & 17 & Delayed & TS III & 11.5 & 5 & 0 & 16 \\
\hline 8 & 16 & Immediate & Superline & 6 & 10 & 0.2 & 41 \\
\hline \multirow[t]{2}{*}{9} & 26 & Delayed & CMI & 13 & 5 & 0 & 25 \\
\hline & 27 & Delayed & CMI & 13 & 5 & 0 & 25 \\
\hline
\end{tabular}

CMI: Neobiotec (Seoul, Korea), Osseospeed: Dentsply Implants (Mölndal, Sweden), TS III/GS III: Osstem Implant Co. (Busan, Korea), Superline: Dentium (Suwon, Korea).

Ji-Young Lee et al: Clinical evaluation of ridge augmentation using autogenous tooth bone graft material: case series study. J Korean Assoc Oral Maxillofac Surg 2013

a successful clinical result, and that new bone formation was observed as a result of the histological analysis ${ }^{9}$. Considering the successful results observed after treatment using graft material and membrane, alveolar ridge augmentation using GBR is considered stable surgery. Thus, the graft material effect and surgical technique of the operator become even more important.

The autogenous tooth bone graft material used in this study was developed in 2008 and has been applied clinically since then. In vitro and animal studies have proven it to be a biocompatible material with osteoinductive and osteoconductive potential $^{10-16}$. Kim et al. ${ }^{6}$ reported that the mineral composition, surface structure, and healing procedure of autogenous tooth bone graft material affected excellent bone healing through guided bone and bone conduction in the scanning electron microscope analysis and histomorphometric research. According to this study, relatively fast and high amount of lamellated bone formation was observed, including bone regeneration in the healing process of autogenous tooth bone graft material. Stabler bone structure had been formed, and noticeable bone formation had been observed after 5 months as a result of the histological analysis ${ }^{6}$. Through a variety of clinical research studies and case reports, clinical evidences supporting the use of autogenous tooth bone graft material were secured ${ }^{14-25}$.

According to Kim et al. ${ }^{18}$, both powder type and block type showed excellent result in socket preservation and good bone healing effect in cases wherein autogenous tooth bone graft material was used in socket preservation and bone reconstruction. They also presented a case of guided bone regeneration using autogenous tooth bone graft material in the posterior mandible and reported that the graft material had been slowly absorbed and replaced by new bone. The study also showed that the new bone and residual graft material had formed a direct union in the histological analysis of the graft area $^{19}$.

Another paper reported that autogenous tooth bone graft material was highly resistant to infection, and that favorable secondary healing was observed at the wound dehiscence site. Moreover, its biocompatibility was reported to be excellent since there was no foreign body reaction such as infection for over 2 years' follow-up after the bone graft ${ }^{24}$. Stable marginal bone status around the implant placed in the bone graft area with AutoBT had been reported as well ${ }^{25}$. 
In this study, vertical or horizontal bone augmentation using AutoBT was performed on 9 patients. There were no complications related to bone graft material, such as infection; wound dehiscence also showed good secondary healing. Although one implant was removed in one patient after nine months of prosthesis due to osseointegration failure, such was deemed to be due to smoking and immoderate mastication by the patient. Since the downward bone status was good, the replacement of implant was completed with successful prosthesis.

This study had limits because evaluations before and after alveolar ridge augmentation had not been conducted. The number of cases was also small, and the observation period was short. Moreover, comparison between the result of ridge augmentation with other typical bone graft material and tooth bone graft material had not been done. Long-term observation research studies that can supplement the results of this study will be necessary. Within the limits of this study, however, AutoBT is considered to be useful in hard tissue reconstructive surgery such as guided bone regeneration, sinus bone graft, and ridge augmentation.

\section{Conclusion}

As a result of performing ridge augmentation using autogenous tooth bone graft material, successful bone healing was observed, and marginal bone around the fixture after implant placement was kept stable as well.

A successful clinical result can be expected with the proper use of AutoBT block and powder type during bone augmentation even in an area with serious alveolar bone resorption, aside from bone defect around the implant.

\section{References}

1. Simion M, Trisi P, Piattelli A. Vertical ridge augmentation using a membrane technique associated with osseointegrated implants. Int J Periodontics Restorative Dent 1994;14:496-511.

2. Tinti C, Parma-Benfenati S, Polizzi G. Vertical ridge augmentation: what is the limit? Int J Periodontics Restorative Dent 1996;16:220-9.

3. Simion M, Jovanovic SA, Tinti C, Benfenati SP. Long-term evaluation of osseointegrated implants inserted at the time or after vertical ridge augmentation. A retrospective study on 123 implants with 1-5 year follow-up. Clin Oral Implants Res 2001;12:35-45.

4. Chiapasco M, Romeo E, Casentini P, Rimondini L. Alveolar distraction osteogenesis vs. vertical guided bone regeneration for the correction of vertically deficient edentulous ridges: a 1-3-year prospective study on humans. Clin Oral Implants Res 2004;15:82-95.

5. Kim YK, Lee HJ, Kim SG, Um IW. Development of bone graft material using autogenous teeth. Dent Success 2009;29:586-93.
6. Kim YK, Kim SG, Byeon JH, Lee HJ, Um IU, Lim SC, et al. Development of a novel bone grafting material using autogenous teeth. Oral Surg Oral Med Oral Pathol Oral Radiol Endod 2010; 109:496-503.

7. Hämmerle CH, Jung RE, Yaman D, Lang NP. Ridge augmentation by applying bioresorbable membranes and deproteinized bovine bone mineral: a report of twelve consecutive cases. Clin Oral Implants Res 2008;19:19-25.

8. Urban IA, Nagursky H, Lozada JL. Horizontal ridge augmentation with a resorbable membrane and particulated autogenous bone with or without anorganic bovine bone-derived mineral: a prospective case series in 22 patients. Int J Oral Maxillofac Implants 2011;26: 404-14.

9. Li J, Xuan F, Choi BH, Jeong SM. Minimally invasive ridge augmentation using xenogenous bone blocks in an atrophied posterior mandible: a clinical and histological study. Implant Dent 2013;22:112-6.

10. Kim JY, Kim KW, Um IW, Kim YK, Lee JK. Bone healing capacity of demineralized dentin matrix materials in a mini-pig cranium defect. J Korean Dent Sci 2012;5:21-8.

11. Jeong HR, Hwang JH, Lee JK. Effectiveness of autogenous tooth bone used as a graft material for regeneration of bone in miniature pig. J Korean Assoc Oral Maxillofac Surg 2011;37:375-9.

12. Kim YK, Kim SG, Oh JS, Jin SC, Son JS, Kim SY, et al. Analysis of the inorganic component of autogenous tooth bone graft material. J Nanosci Nanotechnol 2011;11:7442-5.

13. Kim YK, Kim JH, Hwang JY, Um IW, Jeong D, Yun PY. Restoration of calvarial defect using a variety of xenogenous tooth bone graft material: animal study. J Korean Assoc Maxillofac Plast Reconstr Surg 2012;34:299-310.

14. Murata M, Akazawa T, Hino J, Tazaki J, Ito K, Arisue M. Biochemical and histo-morphometrical analyses of bone and cartilage induced by human decalcified dentin matrix and BMP-2. Oral Biol Res 2011;35:9-14.

15. Murata M, Sato D, Hino J, Akazawa T, Tazaki J, Ito K, Arisue M. Acid-insoluble human dentin as carrier material for recombinant human BMP-2. J Biomed Mater Res A 2012;100:571-7.

16. Murata M, Akazawa T, Mitsugi M, Um IW, Kim KW, Kim YK. Human dentin as novel biomaterial for bone regeneration. In: Pignatello R, ed. Biomaterials-physics and chemistry. 1st ed. New York: InTech; 2011:127-40.

17. MA DH, Kim SG, Oh JS, Lee SK, Jeoung ME, Kim JS, et al. Guided bone regeneration at bony defect using familial tooth graft material: case report. Oral Biol Res 2012;36:69-73.

18. Kim YK, Kim SG, Kim KW, Um IW. Extraction socket preservation and reconstruction using autogenous tooth bone graft: case report. J Korean Assoc Maxillofac Plast Reconstr Surg 2011;33:264-9.

19. Kim YK, Lee HJ, Kim KW, Kim SG, Um IW. Guide bone regeneration using autogenous teeth: case reports. J Korean Assoc Oral Maxillofac Surg 2011;37:142-7.

20. Kim YK, Kim SG, Um IW. Vertical and horizontal ridge augmentation using autogenous tooth bone graft materials: case Report. J Korean Assoc Maxillofac Plast Reconstr Surg 2011;33:166-70.

21. Lee JH, Kim SG, Moon SY, Oh JS, Kim YK. Clinical effectiveness of bone grafting material using autogenous tooth: preliminary report. J Korean Assoc Maxillofac Plast Reconstr Surg 2011;33:144-8.

22. Jeong KI, Kim SG, Kim YK, Oh JS, Jeong MA, Park JJ. Clinical study of graft materials using autogenous teeth in maxillary sinus augmentation. Implant Dent 2011;20:471-5.

23. Jeong KI, Kim SG, Oh JS, Lim SC. Maxillary sinus augmentation using autogenous teeth: preliminary report. J Korean Assoc Maxillofac Plast Reconstr Surg 2011;33:256-63.

24. Lee JY, Kim YK. Retrospective cohort study of autogenous tooth bone graft. Oral Biol Res 2012;36:39-43.

25. Kim YK. Bone graft material using teeth. J Korean Assoc Oral Maxillofac Surg 2012;38:134-8. 